\section{Excitation of Mercury Vapour by the Resonance Line.}

IN supplement to my letter in NATURE of Mar. 30, p. 488, under the above title, I have now made a series of experiments, starting with mercury resonance radiation under typical conditions at room temperature. As the temperature of the mercury is progressively raised, and a rapid stream of vapour is generated, the secondary source, originally symmetrical on either side of the primary beam, begins gradually to elongate on the down stream side, until finally it is wholly on this side, being traceable for a distance of about $3 \mathrm{~cm}$. down stream.

Although this result is unexpected, and contrary to prevailing views, the photographic evidence is very clear. I hope to publish the photographs in due course.

RAYLEIGH.

Terling Place, Chelmsford,

Essex, Mar. 30.

\section{Invisible Oxide Films on Metals.}

THE well-known work of Evans on the passivity of metals has led to the conclusion that oxidation can occur at room temperature on copper and iron, giving a film which is too thin to show interference colours. In his lecture to the American Institute of Mining and Metallurgical Engineers (1929) he has remarked that it is logical to suppose that the oxide film has a real existence before any interference tints are shown. Evans quotes the work of Freundlick, Patscheke, and Zocher (Z. physikal. Chem., 128, 321; 1927), who have made pure metallic iron mirrors from iron carbonyl. They find distinct changes in the reflecting power when air is admitted, showing the formation of oxide films of the order of $10^{-7} \mathrm{~cm}$. in thickness.

Müller and Koenigsberger (Phys. Zeit., vol. 5, p. 413; 1904) have found that there is little difference in the reflecting powers of iron in the active and passive states. In my experiments at temperatures at which the iron interference colours are formed very slowly, there is distinct evidence from the reflecting power of surfaces that there is an oxide film present before there is any evidence of interference colours visible to the eye (cf. Proc. Roy. Soc., A, vol. 117, p. 376; 1928).

In the early stages of oxidation the reflecting power of iron, nickel, and copper becomes somewhat smaller over the whole range of the spectrum, but slightly more so at the violet end of the spectrum than in the red, showing the existence of an absorption maximum far away in the ultra-violet region.

During the study of the spectrophotometry of the growth of sulphide films on metallic copper, evidence was obtained strongly supporting Evans's conclusions of the formation of an oxide film at room temperatures. If reduced copper be attacked with a mixture of one volume of hydrogen sulphide and five volumes of air, two complete colour sequences are produced in a few minutes; if, however, the copper surface be left exposed to air for some hours, and then hydrogen sulphide and air admitted, the interference colours are developed very slowly indeed. Only one colour sequence could be observed during a whole day's exposure. In addition there was a general dulling of the colours so formed.

Heating the metal to $300^{\circ} \mathrm{C}$. in a nitrogen vacuum of $10^{-3} \mathrm{~mm}$. did not remove the film. Hence there is clear evidence in support of the conclusion that a thin film of oxide is formed on copper merely on exposure to air at ordinary temperatures.

\section{St. John's College,}

F. Hurn Constiable.

Cambridge.

No. 3102, Vou. 123]

\section{Solutions and Heat Engines.}

The nature of osmotic pressure is a matter of such great importance both to chemists and to physiologists that I must again crave space to reply to the remarks of the reviewer in NATURE of Mar. 23, p. 445 .

In justification of his, or van't Hoff's, account of osmotic pressure, he points to the description in my book of what would happen if a mixture of two gases at atmospheric pressure in a rigid chamber was separated by a rigid septum, permeable by only one of the two gases, from pure gas of the same kind as could permeate, and at the initial pressure of the mixture. The pure gas would pass into the mixture, the pressure of which would rise until the pressure of the penetrating gas was the same in the mixture as outside of it. The gas which penetrates corresponds to the solvent in a solution, and the non-penetrating gas to the solute, while the extra pressure developed in the mixture might be held to correspond to osmotic pressure. May I point out, however, that this extra pressure is due to solvent and not to solute molecules. There is thus in the phenomena no way of escape from the dilemma for van't Hoff's theory which I indicated in my letter. Van 't Hoff's assumption that osmotic pressure is due to extra bombardment press ure of solute molecules is both unintelligible physically and inconsistent with the facts as revealed by the experiments of Morse and Lord Berkeley.

The algebraical statement on page 25 of my book, to which the reviewer objects, is, I maintain, perfectly correct, and I am well content to leave the judgment as to its correctness with readers of the book.

Cherwell, Oxford, Mar. 23.

J. S. HaLdane.

I wILL add only one short note to what I have said. Consider two cases. (1) One atmosphere of hydrogen on each side of the septum and no nitrogen. The osmotic pressure is zero. (2) Two atmospheres of nitrogen inside the chamber and again one atmosphere of hydrogen on each side. This also is an equilibrium case and the osmotic pressure is Two atmospheres. By what wild theory is this attributed to the oNE atmosphere of hydrogen! The Reviewer.

\section{Science and Mathematics.}

THE sentence italicised in the following from a work published in 1877, seems to have anticipated the views of relativists by half a century : "Any kabalist well acquainted with the Pythagorean system of numerals and geometry can demonstrate that the metaphysical views of Plato were based upon the strictest mathematical principles. 'True mathematics,' says the Magicon, 'is something with which all higher sciences are connected; common mathematics is but a deceitful phantasmagoria whose much-praised infallibility only arises from this-that materials, conditions, and references are made its foundation.' . . . As long as exact science confines its observations to physical conditions and proceeds by the Aristotelian method it certainly cannot fail. But, notwithstanding that the world of matter is boundless for us, it still is finite; and thus materialism will turn forever in this vitiated circle, unable to soar higher than the circumference will permit. The cosmological theory of numerals which Pythagoras learned from the Egyptian hierophants is alone able to reconcile the two units, 'matter' and 'spirit,' and cause each to demonstrate the other mathematically." - "Isis Unveiled," i. 7.

W. W. L. 